\title{
Time course of root initiation and development in perennial ryegrass - a new perspective
}

\author{
A.H.K. ROBIN ${ }^{1}$, C. MATTHEW ${ }^{1}$ and J.R. CRUSH $^{2}$ \\ ${ }^{1}$ Institute of Natural Resources, PN433, PB 11222, Palmerston North \\ ${ }^{2}$ AgResearch, Ruakura Research Centre, PB 3123, Hamilton \\ gpb21bau@gmail.com
}

\begin{abstract}
Perennial ryegrass (Lolium perenne) tillers of cultivar 'Alto' were grown in hydroponic culture in winterspring and autumn experiments and roots of known age were individually dissected and a number of properties including dry weight, main axis length and total length were measured to define root developmental status at successive positions or phytomers on the tiller axis. Root initiation occurred about 5 leaf appearance intervals after leaf emergence at the same phytomer and co-located on the tiller axis with leaf senescence. Root development exhibited co-ordination between successive phytomers as previously described for leaf turnover, but with approximately five adjacent roots developing at any one time. There was little or no root main axis elongation later than six leaf appearance intervals from root initiation, though total length of roots continued to increase for a longer period, especially in autumn.
\end{abstract}

Keywords: Lolium perenne, phytomer, root development, root length, tiller axis position

\section{Introduction}

There has recently been a resurgence of activity in the study of root systems of forage and turf grasses driven by the need to make better use of available water and to improve nutrient capture by plants. For example, Bonos et al. (2004) and Crush et al. (2007; 2010a) have investigated inherited differences in root depth distribution in perennial ryegrass and tall fescue, while Turner et al. (2007) have studied the contribution of carbohydrates from the root system to regrowth after defoliation in prairie grass (Bromus willdenowii). Knowledge of depth distribution and functional contribution of forage grass root systems has therefore increased, but there is little information about the mechanics of root turnover in terms of the location of sites for root formation, the time taken for a root to develop, and the changes in root morphology that would result in a deeper or shallower root system. Some New Zealand studies (e.g. Jacques \& Schwass 1956; Caradus \& Evans 1977) indicated an annual root formation event commencing in autumn with roots elongating over an extended period thereafter.
Other studies, both in the field (Matthew et al. 1991) and examining the detail of the segmental structure of the tiller axis (Matthew et al. 1998; Lattanzi et al. 2005) have suggested root initiation to be a continuous process, involving coordination between successive sites bearing roots at the base of the tiller axis, much like the now well known leaf turnover cycle (Fulkerson \& Donaghy 2001). Segmental units of the tiller axis that provide sites for leaf and root appearance are often referred to as phytomers in the literature and we use this term hereafter.

Clearly the value of data from studies such as those of Crush et al. (2007) and Turner et al. (2007) would be enhanced if there was a more detailed understanding of the normal morphology and timing of root initiation to aid interpretation. Accordingly, the present study was designed to provide a description of the root formation process in perennial ryegrass. In this paper we present winter-spring and autumn data for one cultivar from a larger experiment which included a second cultivar.

\section{Materials and Methods}

Conceptually, our approach to describing the root system was to record dates of leaf appearance for the main tillers of a population of perennial ryegrass plants in hydroponic culture allowing sufficient time for phytomers for which leaf appearance had been observed to produce roots. Thus, the age of each root initiation site of main tillers in the plant population was known, though not necessarily the timing of root initiation. Plants were then destructively harvested and individual roots sorted according to their tiller axis position and development.

Two experiments were conducted using plants grown hydroponically in a glasshouse under natural light: Experiment 1 from 1 July to 28 September 2008 and Experiment 2 from 3 March to 31 May 2009. Mean daily temperature ranged from a low of $5^{\circ} \mathrm{C}$ to a high of 17 ${ }^{\circ} \mathrm{C}$ in Experiment 1, and from a high of $26^{\circ} \mathrm{C}$ to a low of $12^{\circ} \mathrm{C}$ in Experiment 2 . The hydroponic culture unit was described by Khaembah et al. (2008). The following nutrient composition was used: $1 \mathrm{mM} \mathrm{NH} \mathrm{NO}_{3}, 0.6 \mathrm{mM}$ $\mathrm{NaH}_{2} \mathrm{PO}_{4} \cdot \mathrm{H}_{2} \mathrm{O}, 0.6 \mathrm{mM} \mathrm{MgCl} \cdot \mathrm{H}_{2} \mathrm{O}, 0.3 \mathrm{mM} \mathrm{K} \mathrm{SO}_{4}$,

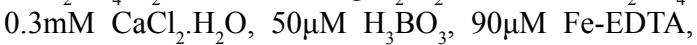


Figure 1 Map of the tiller axis of perennial ryegrass cv. 'Alto' at destructive harvest in Experiment 1 and Experiment 2. $\mathrm{P}$ denotes position number (phytomer) on the tiller axis with the emerging leaf designated 1. Shading indicates presence of a leaf and bold border indicates presence of one or more roots at that phytomer. $T_{L}$ and $T_{R}$ denote age (days) of the leaf and root, respectively, at each position. The delay (days) between leaf and root appearance at a particular phytomer position is shown by $d .1^{\text {st }}$ root after tr. denotes position of first root formed after transplanting to the hydroponic system. For dimensions of individual roots, see Table 2 .

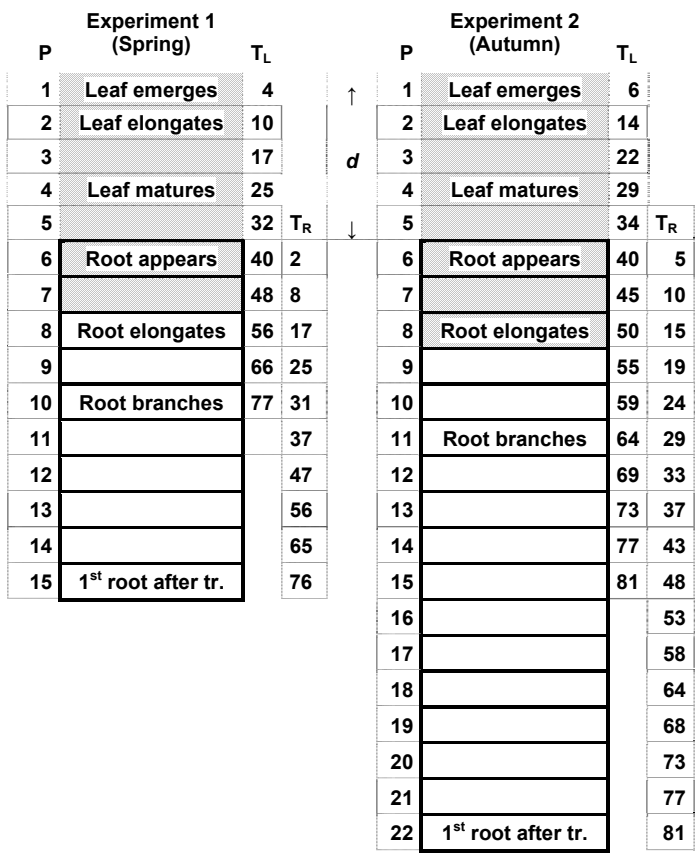

$9 \mu \mathrm{M} \quad \mathrm{MnSO}_{4} \cdot 4 \mathrm{H}_{2} \mathrm{O}, \quad 0.7 \mu \mathrm{M} \quad \mathrm{ZnSO} 4.7 \mathrm{H}_{2} \mathrm{O}, \quad 0.3 \mu \mathrm{M}$ $\mathrm{CuSO}_{4} \cdot 5 \mathrm{H}_{2} \mathrm{O}, 0.1 \mu \mathrm{M} \mathrm{NaMoO}_{4} \cdot 2 \mathrm{H}_{2} \mathrm{O}$ dissolved in tap water. A pH stabiliser, $2 \mathrm{mM}$ MES (2-(N-morpholino) ethanesulfonic acid), was added with the nutrients. The nutrient solution was refreshed weekly and the solution $\mathrm{pH}$ adjusted to 5.5 with $\mathrm{HCl}$.

In Experiment 1 leaf appearance data were recorded for 27 plants (9 genotypes x 3 clonal replicates) of the perennial ryegrass cultivar 'Alto' (NZ Agriseeds Ltd.). Plants were endophyte-positive. In Experiment 2 leaf appearance data were recorded for three clonal replicates of 10 genotypes of 'Alto'. The two experiments included a similar number of plants of a UK-bred cultivar 'Aberdart' (data not reported). Plants were allowed to grow the first two primary daughter tillers and other tillers appearing on the main axis above the first two daughter tillers were removed to facilitate later separation of individual roots. All 27 plants in Experiment 1 and 2 clonal replicates of 8 genotypes in Experiment 2 were dissected under $15 \mathrm{x}$ magnification to isolate individual roots. A tiller axis map for dissected plants was constructed, indicating the number of potential root formation sites or phytomers on the tiller axis (assuming one leaf per phytomer), and their age. Tiller axis positions were counted from youngest to oldest, with the emerging leaf designated position one (Fig. 1). The number of roots per phytomer $(\mathrm{Rn})$, and the root length as determined by the grid intersect method (Tennant 1975) were also recorded. Additionally, live leaves present on the tiller axis at the time of destructive harvesting were measured to determine leaf area by the formula: $0.7(l \times w)$, where $l$ denotes leaf length and $w$ denotes leaf width. A similar 'form factor' to determine cereal leaf area as a fraction of the product of leaf length and width is discussed by Bryson et al. (1997). Leaves were then dried for $48 \mathrm{~h}$ in a draught oven at $60^{\circ} \mathrm{C}$, and weighed. Once isolated, individual roots were labelled to indicate the plant and tiller axis position they came from, and were stored in $70 \%$ ethyl alcohol for later measurement.

For two arbitrarily selected genotypes in Experiment 1 , individual roots at each phytomer were scanned using Winrhizo $^{\circledR}$ software at AgResearch Ruakura (Nichols \& Crush 2007), to collect data on total root length and surface area. A similar procedure was followed in Experiment 2 except that only roots of odd numbered phytomers were scanned because tiller axes had more root-bearing phytomers, causing time constraints. There were 50 individual roots scanned in Experiment 1 and 51 in Experiment 2. To gain a measure of branching the numbers of tips per root were counted using Videopro ${ }^{\circledR}$ software. Following scanning of all roots, their dry weight was determined after drying for $48 \mathrm{~h}$ in a draught oven at $60{ }^{\circ} \mathrm{C}$, and assuming $22 \%$ loss of root weight during storage in ethyl alcohol (Crush et al. 2010b). The total number of roots for which dry weight (RDW) was individually determined was 523 .

Statistical analyses were carried out using the general linear model command of Version 15 of the Minitab software package (Minitab Inc. State College, Pennsylvania). Table 2 data were analysed using a nested ANOVA model with the clonal replicate plants as the experimental units for testing differences in root dimensions between genotypes within each experiment. Because most root properties measured differed substantially between younger and older roots, data (except Rn) were log transformed before ANOVA, and standard errors from ANOVA of log data were back transformed to express the standard errors as ratios of the original mean values.

To test for differences in root morphology between experiments and between genotypes within experiments, root data including some not presented in Table 2 such as numbers of tips per root, were entered 
into a principal component (PC) analysis using the default PCA command of Minitab Version 15, and ANOVA performed on PC scores.

\section{Results}

In Experiment 1 (winter-spring) roots were present, on average, from phytomers $6-15$ on the tiller axis with 75 days being the oldest root at destructive harvest. In Experiment 2 roots were present at phytomers 6 22 and the age of the oldest root was estimated to be 81 days on average (Fig.1). Plant structure differed between experiments, with destructively harvested main tillers in Experiment 1 having about 15 phytomers, seven live leaves, and the first root at phytomer 5 . In Experiment 2 (autumn) the first root appeared at phytomer 6 , but plants had on average 22 phytomers and eight live leaves (Table 1). In Experiment 1 the data indicate rapid root development in the first three leaf appearance intervals after root initiation and little change to observed morphology after five or six leaf appearance intervals from root initiation. The average root dimensions for older roots at phytomers $11-13$ below the emerging leaf were $18 \mathrm{mg} \mathrm{RDW}, 43 \mathrm{~cm}$ main root axis length, $367 \mathrm{~cm}$ total root length, and 36 $\mathrm{cm}^{2}$ root surface area. The youngest mature leaf of the same plants averaged $57 \mathrm{mg}$ DW and $13 \mathrm{~cm}^{2}$ leaf area. In Experiment 2, there was not a clear maximum for total root length, but main axis length again reached its maximum within six leaf appearance intervals of root initiation. Root dimensions for phytomers 11-13 in Experiment 2 were $13 \mathrm{mg}$ dry weight, $48 \mathrm{~cm}$ main axis length, $188 \mathrm{~cm}$ total length, and $21 \mathrm{~cm}^{2}$ surface

Table 1 Number of tiller axis positions (phytomers) for which leaf appearance $\left(L_{A}\right)$ was recorded, number of live leaves $\left(L_{L}\right)$, number of root-bearing phytomers $\left(\mathrm{L}_{\mathrm{B}}\right)$, delay between leaf and root appearance $(d)$, and total number of phytomer positions $(P)$ for plants of perennial ryegrass cv. 'Alto' in Experiment 1 and Experiment 2 conducted in winter-spring and autumn, respectively.

\begin{tabular}{llllll}
\hline & $\mathrm{L}_{\mathrm{A}}$ & $\mathrm{L}_{\mathrm{L}}$ & $\mathrm{L}_{\mathrm{R}}$ & $\mathrm{d}$ & $\mathrm{P}$ \\
\hline Experiment 1 & 9.7 & 6.9 & 9.7 & 5.3 & 15.0 \\
Experiment 2 & 14.8 & 8.4 & 16.8 & 4.8 & 21.6 \\
$\mathrm{P}$ & $<0.001$ & $<0.001$ & $<0.001$ & $\mathrm{NS}$ & $<0.001$ \\
\hline
\end{tabular}

Table 2 Developmental succession of leaves and roots on the tiller axis in Experiment 1 (winter-spring), as indicated by leaf dry weight (LDW), leaf area (LA), number of roots per node $(R n)$, root dry weight per node (RDW), main axis length (MAL), total root length (TRL), and total root surface area (RSA) of individual roots at each position or phytomer (p). TRL and RSA were determined by WinRhizo ${ }^{\circ}$ scanning. Also calculated was daily root dry matter deposition rate (DMD, mg/ phytomer/d) for all roots at each phytomer.

\begin{tabular}{|c|c|c|c|c|c|c|c|c|}
\hline $\mathrm{P}$ & $\begin{array}{c}\text { LDW } \\
\mathrm{Mg}\end{array}$ & $\begin{array}{c}\text { LA } \\
\mathrm{cm}^{2}\end{array}$ & $\mathrm{Rn}$ & $\begin{array}{c}\text { RDW } \\
\text { mg }\end{array}$ & $\begin{array}{c}\mathrm{MAL} \\
\mathrm{cm}\end{array}$ & $\begin{array}{c}\mathrm{TRL} \\
\mathrm{cm}\end{array}$ & $\begin{array}{l}\mathrm{RSA} \\
\mathrm{cm}^{2}\end{array}$ & $\begin{array}{c}\mathrm{DMD} \\
\mathrm{mg} / \mathrm{p} / \mathrm{d}\end{array}$ \\
\hline 1 & 24 & 5.3 & & & & & & \\
\hline 2 & 57 & 13.2 & & & & & & \\
\hline 3 & 57 & 12.6 & & & & & & \\
\hline 4 & 52 & 10.8 & & & & & & \\
\hline 5 & 47 & 9.2 & & & & & & \\
\hline 6 & 40 & 9.2 & 2.0 & 1.4 & 6 & 1.25 & 0.3 & 1.22 \\
\hline 7 & 35 & 5.3 & 1.7 & 5.7 & 26 & 184 & 21.4 & 0.85 \\
\hline 8 & & & 1.7 & 8.5 & 29 & 300 & 27.1 & 0.58 \\
\hline 9 & & & 1.6 & 11.0 & 33 & 137 & 11.2 & 0.46 \\
\hline 10 & & & 1.5 & 14.2 & 38 & 429 & 33.8 & 0.24 \\
\hline 11 & & & 1.6 & 18.7 & 41 & 288 & 31.5 & 0.07 \\
\hline 12 & & & 1.4 & 19.5 & 45 & 371 & 30.4 & \\
\hline 13 & & & 1.4 & 15.2 & 43 & 442 & 45.4 & \\
\hline 14 & & & 1.2 & 20.9 & 42 & 365 & 27.7 & \\
\hline 15 & & & 1.1 & 12.5 & 40 & 472 & 35.4 & \\
\hline Total $^{1}$ & 312 & 69 & 15.2 & 191 & - & 4240 & 380 & - \\
\hline $\mathrm{SE}^{2}$ & $1.8 \%$ & $2.8 \%$ & 0.056 & $4.5 \%$ & $9.4 \%$ & $12.7 \%$ & $11.2 \%$ & $10.3 \%$ \\
\hline
\end{tabular}

${ }^{1}$ Totals calculated on a per phytomer basis taking account of Rn. For total root length and root surface area.

${ }^{2}$ Standard error of mean; where given as $\%$ is for log transformed data. For statistical probability values please see notes to Table 3. 
Table 3 Developmental succession of leaves and roots on the tiller axis in Experiment 2 (autumn). Abbreviations are as for Table 2.

\begin{tabular}{|c|c|c|c|c|c|c|c|c|}
\hline $\mathrm{P}$ & $\begin{array}{c}\text { LDW } \\
\text { Mg }\end{array}$ & $\begin{array}{c}\mathrm{LA} \\
\mathrm{cm}^{2}\end{array}$ & $\mathrm{Rn}$ & $\begin{array}{c}\text { RDW } \\
\text { mg }\end{array}$ & $\begin{array}{c}\mathrm{MAL} \\
\mathrm{cm}\end{array}$ & $\begin{array}{l}\mathrm{TRL} \\
\mathrm{cm}\end{array}$ & $\begin{array}{l}\mathrm{RSA} \\
\mathrm{cm}^{2}\end{array}$ & $\begin{array}{c}\text { DMD } \\
\mathrm{mg} / \mathrm{p} / \mathrm{d}\end{array}$ \\
\hline 1 & 39 & 6.5 & & & & & & \\
\hline 2 & 100 & 15.4 & & & & & & \\
\hline 3 & 109 & 16.9 & & & & & & \\
\hline 4 & 106 & 16.3 & & & & & & \\
\hline 5 & 103 & 15.7 & & & & & & \\
\hline 6 & 99 & 14.4 & 2.3 & 2.7 & 5 & & & 0.53 \\
\hline 7 & 92 & 12.7 & 2.6 & 5.7 & 14 & 8 & 2.1 & 0.54 \\
\hline 8 & 80 & 10.8 & 2.5 & 7.4 & 29 & & & 0.42 \\
\hline 9 & & & 2.7 & 11.4 & 34 & 47 & 8.1 & 0.59 \\
\hline 10 & & & 2.5 & 11.2 & 41 & & & 0.42 \\
\hline 11 & & & 2.6 & 12.9 & 47 & 153 & 19.1 & 0.43 \\
\hline 12 & & & 2.3 & 13.7 & 49 & & & 0.34 \\
\hline 13 & & & 2.0 & 13.0 & 47 & 222 & 22.5 & 0.26 \\
\hline 14 & & & 2.0 & 17.8 & 50 & & & 0.22 \\
\hline 15 & & & 1.8 & 18.2 & 50 & 173 & 23.4 & 0.09 \\
\hline 16 & & & 1.9 & 18.3 & 48 & & & 0.01 \\
\hline 17 & & & 2.1 & 16.9 & 47 & 217 & 21.9 & \\
\hline 18 & & & 2.2 & 13.8 & 43 & & & \\
\hline 19 & & & 2.4 & 16.8 & 41 & 298 & 22.3 & \\
\hline 20 & & & 2.8 & 16.9 & 38 & & & \\
\hline 21 & & & 3.1 & 16.9 & 37 & 383 & 29.3 & \\
\hline 22 & & & 2.4 & 10.9 & 36 & & & \\
\hline Total $^{1}$ & 728 & 109 & 40.2 & 521 & - & 7320 & 708 & - \\
\hline $\mathrm{SE}^{2}$ & $2.2 \%$ & $2.8 \%$ & 0.052 & $4.5 \%$ & $6.8 \%$ & $15.4 \%$ & $13.3 \%$ & $11.0 \%$ \\
\hline$P(\operatorname{Exp})^{3}$ & $<0.001$ & $<0.001$ & $<0.001$ & NS & 0.029 & NS & NS & NS \\
\hline $\mathrm{P}(\mathrm{Gen})^{4}$ & 0.027 & NS & NS & 0.007 & - & - & - & NS \\
\hline$P(\text { Phy })^{5}$ & $<0.001$ & NS & NS & $<0.001$ & NS & NS & NS & 0.002 \\
\hline
\end{tabular}

${ }^{1}$ Totals calculated on a per phytomer basis taking account of Rn. For total root length and root surface area, Experiment 2 total was considered to be $2 x$ sum of measured phytomers.

${ }^{2}$ Standard error of mean; where given as $\%$ is for log transformed data.

${ }^{3} \mathrm{P}(\mathrm{Exp})$ indicates significance of the difference between Experiments $1 \& 2$.

${ }^{4} \mathrm{P}(\mathrm{Gen})$ significance of difference between genotypes within experiments.

${ }^{5} \mathrm{P}(\mathrm{Phy})$ indicates significance of variation between phytomer positions

area, with the youngest leaf being $100 \mathrm{mg}$ dry weight and $15 \mathrm{~cm}^{2}$ in area (Tables $2 \& 3$ ). Figs. $2 \mathrm{a} \& 2 \mathrm{~b}$ show a single root from phytomers eight and 12, respectively, of the same genotype in Experiment 1. Root number averaged 1.5 per phytomer in Experiment 1 and 2.5 in Experiment 2 (Tables $2 \& 3$ ). Individual roots tended to have less dry weight, total length and surface area in Experiment 2 than in Experiment 1 where root number per phytomer was lower (Tables $2 \& 3$ ).

Though highly statistically significant, differences in root morphology between experiments or between genotypes within experiments were visually subtle. The tests for differences in root morphology using PCA yielded two principal components (PCs $1 \& 3$ ) for which scores differed significantly between experiments and genotypes. PC1 discriminated between roots based on root size and root age while PC3, considered to be more interesting from an agronomic perspective, discriminated between roots whose properties included finer diameter and greater dry weight, and so greater length, compared with roots of coarser diameter, lesser dry weight and reduced length. Figs. $2 b \& 2 c$ illustrate roots of phytomer position 12 of different genotypes from Experiment 1, but with contrasting scores for PC3. Fig. 2d illustrates a root of phytomer 16 from a plant in Experiment 2. Phytomer 16 in Experiment 2 was of similar age, see Fig. 1, to phytomer 12 in Experiment 1, shown in Fig. $2 b$. 
Figure 2 Individual roots of perennial ryegrass cv. 'Alto': (a) from position or phytomer eight (the $3^{\text {rd }}$ root-bearing phytomer) and (b) from phytomer 12 (four leaf appearance intervals older) of the same plant genotype in Experiment 1; (c) from phytomer 12 of a genotype in Experiment 1 identified by principal component analysis (see text) as having differing morphology from (b); (d) from phytomer 16 in Experiment 2 (autumn), with roots of similar age to phytomer12 in Experiment 1.
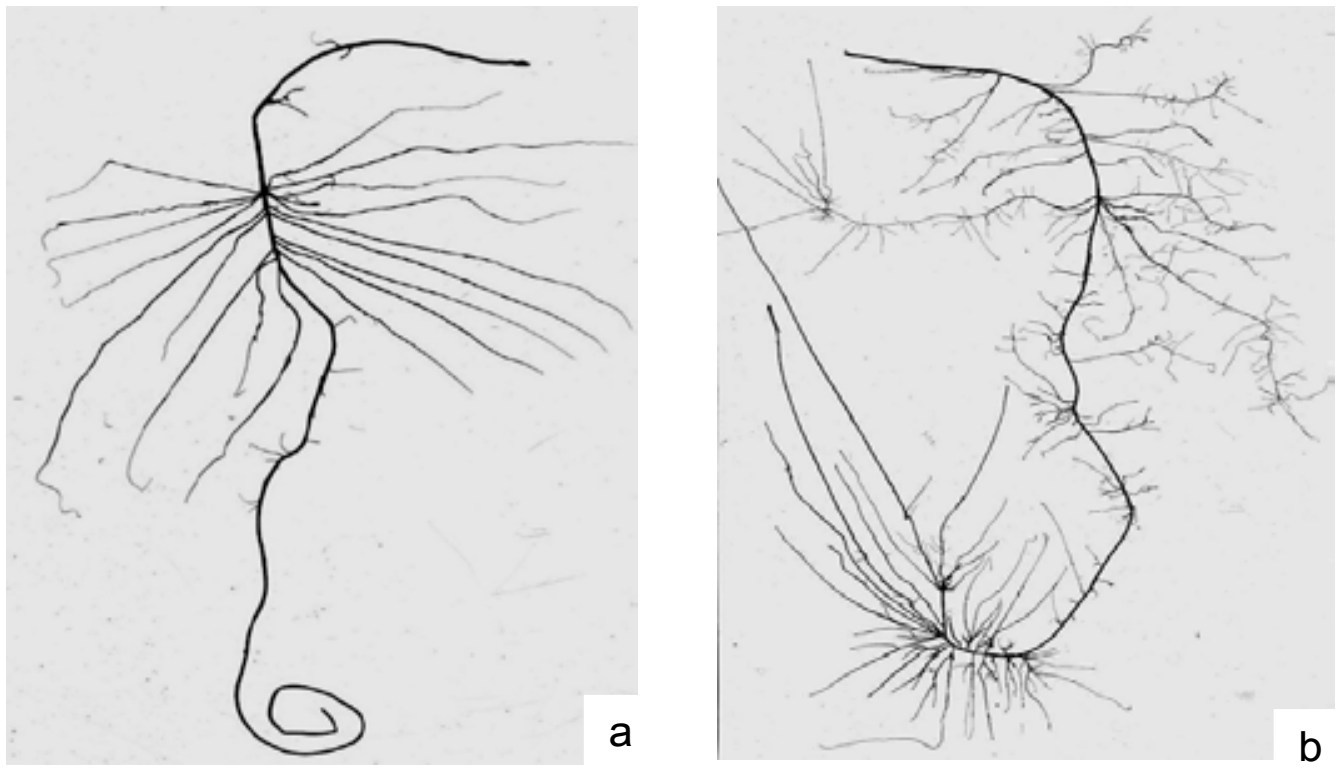

\section{Root Statistics}

Dry weight $(\mathrm{mg})$

Main axis length $(\mathrm{cm})$

Total length $(\mathrm{cm})$

Surface Area $\left(\mathrm{cm}^{2}\right)$

Mean diameter $(\mathrm{mm})$

Volume $\left(\mathrm{mm}^{3}\right)$

Number of Tips

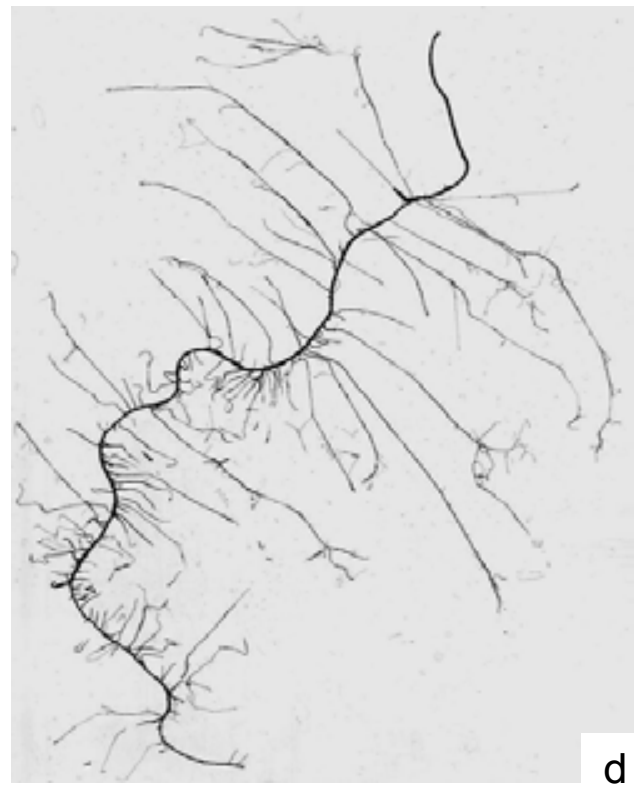

b

C

d

32
52
549
43
0.25
270
275

25

46

477

44

0.30

330

181

28

36

423

31

0.24

186

194

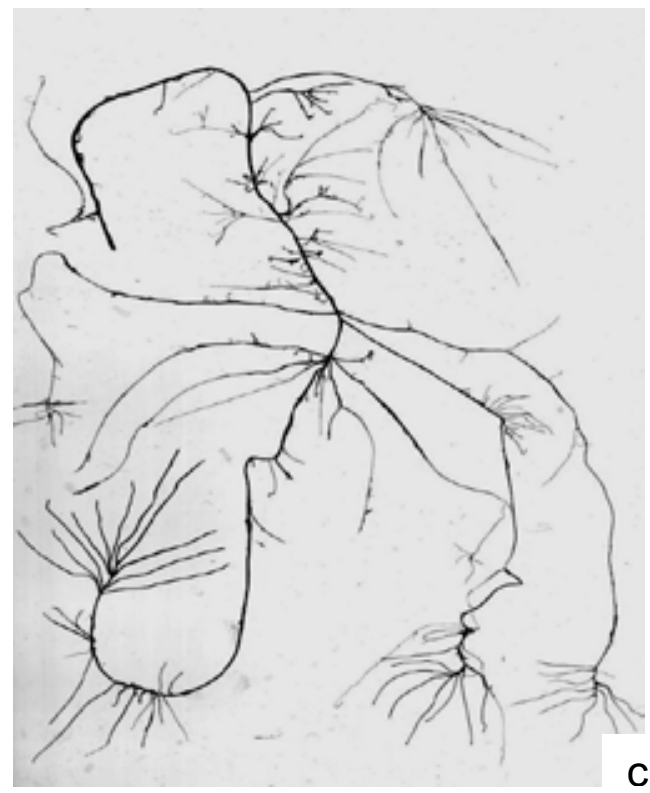




\section{Discussion}

The work reported here provides an integrated overview of leaf and root growth in perennial ryegrass as successive events on individual phytomers within a coordinated series of phytomers on the tiller axis (Fig. 1). One key finding from these two experiments is that the majority of root growth occurs in a time period of about six leaf appearance intervals, commencing for a given phytomer around the time of leaf senescence on that phytomer. Within the tiller axis zone of rapid root formation, there is coordination between phytomers in that the root(s) located on a given phytomer are typically more developed than those on the next youngest phytomer immediately above. Such coordination between phytomers is now well understood in relation to leaf development (Fournier et al. 2005; Verdenal et al. 2008). The present experiment did not continue long enough to observe root death.

The extent to which the data are actually representative of processes in field swards where temperature moisture and nutrient supply can vary temporally and spatially requires further research. Our plants in the hydroponic system comprising a main stem and one primary daughter tiller developed a large tiller size compared to plants in field swards, with approximately double the number of live leaves per tiller described by Fulkerson \& Donaghy (2001). Against these caveats, the key inferences about root development drawn from data in Tables $2 \&$ 3, agree with results from a small study of Matthew \& Kemball (1997) on perennial ryegrass plants grown in a soil-based medium and with a more typical growth habit.

Another point of interest was that in no case in either experiment, was a main root axis length of more than $50 \mathrm{~cm}$ observed, yet there was an indication of ongoing increase in the length of lateral branches (as reflected in total root length) after main axis elongation ceased, especially in Experiment 2. In the experiment of Matthew \& Kemball (1997) feeding of ${ }^{14} \mathrm{CO}_{2}$ to leaves and subsequent recovery and quantification in individual roots indicated that the majority of current photosynthate moving down the tiller axis was intercepted by roots at the first few root bearing phytomers, with little reaching older roots. Daughter tillers may, however, feed the older roots of their parent tillers, as has been shown in a tropical grass species (Carvalho et al. 2006). Hence it may be that pruning of daughter tillers reduced main axis length for roots of the tillers studied in these experiments. Since, ryegrass root systems have been observed in other studies to penetrate to over one metre in depth (Jacques 1943), this raises questions for further research relating to the relative contribution of the main axis and branch roots to soil depth penetration.
Another key finding is that highly significant plant genotype differences in root morphology detected by PCA of root morphology data from Winrhizo ${ }^{\circledR}$ scanning were visually subtle (Fig. 2). Given that the average weight of leaf sheath per tiller was $130 \mathrm{mg}$ for Experiment 1 and $229 \mathrm{mg}$ for Experiment 2, per tiller totals for leaf and root (Tables $2 \& 3$ ) indicate a root:shoot dry weight ratios of 0.43 and 0.54 , and root:shoot area ratios of 5.5 and 6.5 for Experiments 1 and 2, respectively. Although it is well understood that nutrient uptake requires large areas compared to light capture, quantitative data are few. Moreover, this comparison ignores the contribution to root surface area of root hairs. Another point of interest is the source of the energy and nutrients for ongoing increase in total root length when parent tiller supply to a root is reduced because younger roots obtain most of the resources flowing downwards before they reach older roots lower on the tiller axis.

In conclusion the current data indicate that the normal pattern for perennial ryegrass root dynamics is one involving continual formation of new roots, with new root development coordinated between adjacent phytomers, much as occurs in leaf development. In contrast to the leaf development process, root development normally occurs simultaneously on several adjacent phytomers. Although ryegrass root growing points are theoretically indeterminant, continued elongation of main root axes appears to be limited by the capture of photosynthate by younger roots forming above them on the tiller axis. Questions for further research arising from these results include (i) how to use knowledge of the site and timing of root formation on the tiller axis to formulate grazing management strategies that favour a stronger root system, (ii) details of the carbon economy of older roots, and (iii) whether further investigation to clarify the functional significance of differences in root morphology may make it possible in future to select for desirable root system characteristics.

\section{ACKNOWLEDGEMENTS}

AHKR thanks Massey University for the award of a Vice Chancellor's doctoral scholarship and Bangladesh Agricultural University for granting study leave to undertake this work. Additional support from the T.R. Ellett Agricultural Research Trust is gratefully acknowledged. Thanks to S. Ray, L. Sylva, and L. Taylor for assistance with plant culture.

\section{REFERENCES}

Bonos, S.A.; Rush, D.; Hignight, K.; Meyer, W.A. 2004. Selection for deep root production in tall fescue and perennial ryegrass. Crop Science 44: 1770-1775. Bryson, R.J.; Pavely, N.D.; Clark, W.S.; Sylvester- 
Bradley, R.; Scott, R.K. 1997. Use of in-field measurements of green leaf area and incident radiation to estimate the effects of yellow rust epidemics on the yield of winter wheat. European Journal of Agronomy 7: 53-62.

Caradus, J.R.; Evans, P.S. 1977. Seasonal root formation of white clover, ryegrass and cocksfoot in New Zealand. New Zealand Journal of Agricultural Research 20: 337-342.

Carvalho, D.D.; Irving, L.J.; Carnevalli, R.A.; Hodgson, J.; Matthew, C. 2006. Distribution of current photosynthate in two Guinea grass (Panicum maximum Jacq.) cultivars. Journal of Experimental Botany 57: 2015-2024.

Crush, J.R.; Easton, H.S.; Waller, J.E.; Hume, D.E.; Faville, M.J. 2007. Genotypic variation in patterns of root distribution, nitrate interception and response to moisture stress of a perennial ryegrass (Lolium perenne L.) mapping population. Grass and Forage Science 62: 265-273.

Crush, J.R.; Nichols, S.N.; Ouyang, L. 2010a. Adventitious root mass distribution in progeny of four perennial ryegrass (Lolium perenne L.) groups selected for root shape. New Zealand Journal of Agricultural Research 53: 193-200.

Crush, J.; Ouyang, L.; Nichols, S. 2010b. Loss of weight in ryegrass and clover roots preserved in ethanol prior to image analysis for root traits. Acta Physiologiae Plantarum 32: 605-606.

Fournier, C.; Durand, J.L.; Ljutovac, S.; Schäufele, R.; Gastal, F.; Andrieu, B. 2005. A functionalstructural model of elongation of the grass leaf and its relationships with the phyllochron. New Phytologist 166: 881-894.

Fulkerson, W.J.; Donaghy, D.J. 2001. Plant-soluble carbohydrate reserves and senescence - key criteria for developing an effective grazing management system for ryegrass-based pastures: a review. Australian Journal of Experimental Agriculture 41: 261-275.

Jacques, W.A. 1943. Root development in some common New Zealand pasture plants II. Perennial ryegrass (Lolium perenne) cocksfoot (Dactylis glomerata) and white clover (Trifolium repens). New Zealand Journal of Science and Technology A25: 91-117.

Jacques, W.A.; Schwass, R.H. 1956. Root development in some common New Zealand pasture plants VII. Seasonal root replacement of perennial ryegrass (Lolium perenne) Italian ryegrass (L. multiflorum) and tall fescue (Festuca arundinacea). New Zealand Journal of Science and Technology A37: 569-583.
Khaembah, E.N.; Irving, L.J.; Thom, E.R.; Matthew, C. 2008. Rubisco turnover and its relationship with herbage yield traits in perennial ryegrass (Lolium perenne L.). Proceedings of the New Zealand Grassland Association 70: 205-209.

Lattanzi, F.A.; Thornton, B.; Schnyder, H. 2005. Functional heterogeneity within grass roots systems. Comparative Biochemistry and Physiology A - Molecular \& Integrative Physiology 141 (Supplement): S223-S224.

Matthew, C.; Kemball, W.D. 1997. Allocation of carbon-14 to roots of different ages in perennial ryegrass (Lolium perenne L.). Proceedings of the XVIII International Grassland Congress, Calgary: Association Management Centre, Section 7, 1-2.

Matthew, C.; Yang, J.Z.; Potter, J.F. 1998. Determination of tiller and root appearance in perennial ryegrass (Lolium perenne) swards by observation of the tiller axis, and potential application in mechanistic modelling. New Zealand Journal of Agricultural Research 41: 1-10.

Matthew, C.; Xia, J.X.; Chu, A.C.P.; Mackay, A.D.; Hodgson, J. 1991. Relationship between root production and tiller appearance rates in perennial ryegrass (Lolium perenne L.). pp. 25-47. In: Plant root growth, an ecological perspective. Ed. Atkinson, D. Blackwell Scientific Publications, Oxford.

Nichols, S.N.; Crush, J.R.; Woodfield, D.R. 2006. Effects of inbreeding on nodal root system morphology and architecture of white clover (Trifolium repens L.). Euphytica 156: 365-373.

Tennant, D. 1975. A test of a modified line intersect method of estimating root length. Journal of Ecology 63: 995-1001.

Turner, L.R.; Donaghy, D.J.; Lane, P.A.; Rawnsley, R.P. 2007. Patterns of leaf and root regrowth, and allocation of water-soluble carbohydrate reserves following defoliation of plants of prairie grass (Bromus willdenowii Kunth.). Grass and Forage Science 62: 497-506.

Verdenal, A.; Combes, D.; Escobar-Gutiérrez, A. 2008. A study of ryegrass architecture as a self-regulated system, using functional-structural plant modelling. Functional Plant Biology 35: 911-924. 
